\title{
El problema no es el aborto, sino el embarazo
}

\section{Antonio Bascuñán ${ }^{1}$}

La naturaleza ha sido injusta en la distribución entre los géneros de la carga por la reproducción de la especie. Los hombres nunca se ven enfrentados, como las mujeres, a tener que optar entre desarrollar una vida sexual activa, mantener intacta su capacidad reproductiva o competir en condiciones de igualdad en el mercado del trabajo. Los hombres pueden gozar o poseer esos bienes simultáneamente; las mujeres, no. Además, tolerar la invasión no consentida del propio cuerpo es algo que ningún ser humano tiene que soportar a favor de otro ser humano. ¿Por qué habrían de tener los seres humanos en estado embrionario o fetal más derechos respecto de las mujeres que los que tenemos todos los nacidos, unos respecto de otros? Es necesario seguir cuatro principios para rectificar esta situación y hacer socialmente justo lo naturalmente injusto. Primero, debemos desarrollar una política social intensa de apoyo al embarazo y la maternidad. Esa política debe representar nuestro mejor esfuerzo por redistribuir la carga que la naturaleza injustamente distribuyó. Segundo, debemos desarrollar una política de salud de intensa cobertura y eficacia en la distribución y acceso de medios anticonceptivos. Esa política debe representar nuestro mejor esfuerzo por dotar a las mujeres de un medio neutral a sus concepciones personales del bien que las proteja del embarazo no deseado. La abstinencia no es un medio moralmente neutral: promoverla implica denigrar los modos de vida alternativos. Tercero, mientras los medios anticonceptivos no sean infalibles, fácilmente reversibles y de acceso absolutamente garantizado, la ley debe conceder a la mujer el mínimo plazo razonable para interrumpir el embarazo: tres meses a contar de la concepción. No se trata de que la vida del embrión o feto sea irrelevante antes de esa fecha. De lo que se trata es de cumplir una condición básica para justificar la exigencia a la mujer de tolerar el embarazo: hacerla responsable de llevar a término el embarazo por haberlo asumido voluntariamente. 
La práctica voluntaria del sexo no basta como condición en este sentido. No hay manera de juzgar verosímilmente si la mujer adoptó o no los medios técnicos razonables para no exponerse al riesgo de un embarazo cuando practicó el sexo. Y sostener que la mera práctica del sexo implica la asunción de ese riesgo confirma la injusta distribución que la naturaleza hizo entre los géneros: los hombres nunca asumen ese riesgo cuando practican el sexo. Las exigencias que la Constitución de 1980 impone en esta materia requieren relacionar el primer principio con el tercer principio mediante lo que se conoce como "consejo forzoso". Es decir, que la autorización a la mujer para interrumpir el embarazo dependa de tener una entrevista previa con un funcionario público cuyo fin sea persuadir a la mujer de llevar el embarazo a su término, informándole de todos los medios de apoyo disponibles. Cuarto, la obligación exigible a la mujer solo es tolerar un embarazo para la supervivencia de otro ser humano; tolerar la probabilidad de mayores riesgos para la salud de los que conlleva normalmente un embarazo no es exigible; tolerar el embarazo de un embrión o feto inviable no es exigible. En estos casos continuar o interrumpir el embarazo debe ser un asunto de libre decisión de la mujer. A estos cuatro principios yo agregaría un quinto, consistente en atenuar las exigencias a la mujer en las primeras semanas de desarrollo del embrión y aumentarlas en las últimas semanas de desarrollo del feto. El inicio del embarazo debería contar aún como cubierto por el ciclo menstrual de la mujer para efectos de su interrupción; al término del embarazo debería contar el feto como ya nacido para efectos de la justificación de su muerte: solo si no se puede evitar de otro modo la muerte de la mujer o un daño gravísimo para su salud. Este principio responde a una concepción gradualista del embrión o feto, o sea, una concepción de menos persona a más persona, que todavía resulta contraintuitiva para muchos. Por eso no lo postulo junto a los otros cuatro principios como un axioma fácilmente accesible para la razón moral de todos los interlocutores.

\section{Nota}

1 Académico de la Facultad de Derecho de la Universidad de Chile. 